\title{
Otolaryngologic Lesions among Human Immunodeficiency Virus-infected Children
}

\author{
Oluwabusayo D. Babatunde ${ }^{1} \quad$ Adebolajo A. Adeyemo $^{1}$ \\ ${ }^{1}$ Institute of Child Health, College of Medicine, University of Ibadan, \\ Ibadan, Nigeria \\ ${ }^{2}$ Department of Pediatrics, College of Medicine, University of \\ Ibadan, Ibadan, Nigeria
}

\author{
Regina E. Oladokun²
}

Ann Otol Neurotol ISO 2018;1:105-110

\begin{abstract}
Address for correspondence Adebolajo A. Adeyemo, MBBS, MSc, FWACS, Institute of Child Health, College of Medicine, University of Ibadan, Ibadan, Nigeria (e-mail: adebolajo@gmail.com).
\end{abstract}

\begin{abstract}
Keywords

- human immunodeficiency virus

- otolaryngology

- pediatric
\end{abstract}

Background Otolaryngologic (ORL) lesions are common in children. ORL lesions occur even more commonly and more severely in HIV-infected children. The few available literature has reported a high prevalence in human immunodeficiency virus (HIV)infected children; however, there are inadequate data on the impact of HIV infection on hearing and the pattern of manifestations of ORL lesions among African children.

Objectives This study was conducted to describe the prevalence and manifestations of ORL lesions among HIV-infected children and controls in Nigeria.

Materials and Methods A prospective comparative cross-sectional study design was adopted. Clinical evaluation was done, and hearing assessment was done using otoacoustic emission for all participants and pure tone audiometry for participants aged $\geq 5$ years. Hearing thresholds were defined according to the World Health Organization classification.

Results One hundred children were studied: 50 HIV-infected and 50 HIV-negative children. The prevalence of ORL lesions among HIV-infected children was $66 \%$, whereas it was $46 \%(p=0.044)$ among HIV-negative children. ORL lesions were more prevalent among children between the 18-month and 5-year age group $(p=0.003)$ irrespective of HIV status. The lesions that were associated with HIV infection were cervical adenopathy $(44 \%, p=0.010)$ and hearing loss $(36 \%, p=0.023)$.

Conclusion The frequency of ORL lesions is high in HIV-infected children, but improved outcomes following use of medications may be responsible for the slight disparity in prevalence when compared with HIV-negative children.

\section{Introduction}

The human immunodeficiency virus (HIV) infection remains a major public health concern worldwide, but sub-Saharan Africa accounts for an estimated $69 \%$ of all HIV infections, making it the most severely affected region. ${ }^{1}$ Currently, Nigeria has the largest burden of pediatric HIV infection, and vertical transmission remains the predominant means of infection among Nigerian children. ${ }^{2-4}$ HIV infection has become a chronic disease due to improved survival as a result of global commitment to control of the disease. Thus, survivors of the disease may develop impairment in different body systems and suffer disabilities., ${ }^{5,6}$ Otolaryngologic (ORL) lesions occur in approximately 40 to $90 \%$

of individuals with HIV infection. ${ }^{7-10}$ Although ORL lesions are common occurrences in children; however, in HIV-infected children, they are more severe, last longer, and are recurrent. These lesions can occur as part of the symptoms of the HIV disease or as complications of disease or treatment. As a result of the challenges of access to diagnostic services in resourcepoor countries, ORL lesions have been considered as possible surrogates of diagnosis of HIV infection. ${ }^{7,11,12}$

In Nigeria, there are few studies on the burden of ORL lesions among the pediatric HIV-infected population. The objective of this study was to describe the prevalence and pattern of ORL lesions among HIV-infected children in comparison with HIV-negative children. 


\section{Materials and Methods}

The study was conducted in a tertiary health facility that receives donor support for pediatric HIV care. A prospective comparative cross-sectional study design was adopted. HIV-infected children and HIV-negative children aged 6 weeks to 14 years were recruited from the Pediatric Infectious Diseases clinic, the General Out-Patient clinic, and the pediatric wards. Ethical approval for this study was obtained from the University of Ibadan and University College Hospital, Ibadan Ethics Committee (UI/UCHEC). Informed consent was obtained before recruitment of participants into the study. Demographic and clinical information was obtained using a semistructured questionnaire. All participants underwent clinical examination of the ears, nose, oral cavity, and neck including otoscopy. Ear swab was taken from children with ear discharge using conventional swab sticks and a Remel A.C.T II swab stick (transport system for aerobic, anaerobic, and facultative microorganisms).

Hearing assessment was done using otoacoustic emission for all participants and pure tone audiometry (PTA) for participants older than 5 years. Audiometry was done at frequencies of $250,500,1,000,2,000,3,000,4,000,6,000 \mathrm{~Hz}$, and $8,000 \mathrm{~Hz}$. Hearing thresholds were defined according to the classification by the World Health Organization (WHO). Slight/mild hearing loss was defined as 26 to $40 \mathrm{~dB}$, moderate hearing loss as 41 to $60 \mathrm{~dB}$, severe hearing loss as 61 to $80 \mathrm{~dB}$, and profound hearing loss as threshold above $81 \mathrm{~dB} \cdot .^{13}$ Conduction hearing loss was described as air conduction PTA $>25 \mathrm{~dB}$ with normal bone conduction and an air-bone gap of $\geq 10 \mathrm{~dB}$. Sensorineural hearing loss was identified as air conduction PTA $>25 \mathrm{~dB}$, bone conduction PTA $>25 \mathrm{~dB}$, and an air-bone gap $<10 \mathrm{~dB}$. Mixed hearing loss was defined as occurrence of impairment of both air and bone conduction and air bone gap $>10 \mathrm{~dB}$.

Acute otitis media (AOM) was defined as ear pain, inflamed tympanum, ear discharge $<2$ weeks, whereas chronic suppurative otitis media (CSOM) was defined as ear discharge of > 2 -week duration or recurrent ear discharge. Cervical adenopathy is defined as any cervical lymph node $>1.5 \mathrm{~cm}$.

\section{Results}

Total 50 HIV-infected and 50 HIV-negative children were studied. In all, there were 55 boys and 45 girls giving a male-to-female ratio of $1.2: 1$. The age range of the participants was 4 months to 15 years, and mean age was 7.4 years \pm 4.6 years. Among the HIV-infected children, 28 (56\%) were orphaned, whereas none of the HIV-negative children were orphaned ( - Table 1). An equal number of $43 \mathrm{HIV-neg-}$ ative and 43 HIV-infected children received routine immunization. Incomplete or no immunization was recorded among four HIV-infected children, whereas the immunization status of three HIV-infected children and seven HIV-negative children was unknown. Overall, $82 \%$ of all the children were well nourished, only $17 \%$ were underweight, and only 1 child was overweight. HIV-infected children accounted for $64.7 \%$ of the underweight children (-Fig. 1).

The mode of transmission of HIV among the infected children was mother to child (vertical) in 94\%. Of the remaining three with horizontal transmission, one was infected via sexual abuse, one was infected after using the toothbrush of her HIV-infected sibling, whereas the third was undetermined. The mean age at HIV diagnosis was 4 years 9 months ( \pm 3 years 10 months). Advanced disease (WHO clinical stages 3 and 4) was observed in 43/50 (86\%) of the HIV-infected

Table 1 Association between participants' characteristics and presence of ORL lesions

\begin{tabular}{|c|c|c|c|c|}
\hline & \multicolumn{3}{|l|}{ ORL lesions } & \multirow[t]{2}{*}{ Chi-square ( $p$-Value) } \\
\hline & Yes (\%) & No (\%) & Total & \\
\hline \multicolumn{5}{|l|}{ HIV status } \\
\hline Infected & $33(66.0)$ & $17(46.0)$ & $50(100)$ & \multirow[t]{2}{*}{$4.0(0.044)^{*}$} \\
\hline Negative & $23(46.0)$ & $27(54.0)$ & $50(100)$ & \\
\hline \multicolumn{5}{|l|}{ Age group } \\
\hline $6 \mathrm{wk}-18 \mathrm{mo}$ & $4(33.3)$ & $8(66.7)$ & $12(100)$ & \multirow[t]{4}{*}{$14.11(0.01)^{*}$} \\
\hline$>18 \mathrm{mo}-5 \mathrm{y}$ & $21(80.8)$ & $5(19.2)$ & $26(100)$ & \\
\hline$>5-10 y$ & $21(61.8)$ & $13(38.2)$ & $34(100)$ & \\
\hline$>10-15 y$ & $10(35.7)$ & $18(64.3)$ & $28(100)$ & \\
\hline \multicolumn{5}{|l|}{ Nutritional status } \\
\hline Undernourished & $13(76.47)$ & $4(23.53)$ & $17(100)$ & \multirow[t]{2}{*}{$3.6(0.06)$} \\
\hline Normal & $42(51.22)$ & $40(48.78)$ & $82(100)$ & \\
\hline \multicolumn{5}{|l|}{ Orphan status } \\
\hline Not orphaned & $43(55.1)$ & 35 (44.9) & $78(100)$ & \multirow[t]{4}{*}{$1.38(0.71)$} \\
\hline Maternal orphan & $7(58.3)$ & $5(41.7)$ & $12(100)$ & \\
\hline Paternal orphan & $1(33.3)$ & $2(66.7)$ & $3(100)$ & \\
\hline Double orphan & $5(71.4)$ & $2(28.6)$ & $7(100)$ & \\
\hline
\end{tabular}

Abbreviations: HIV, human immunodeficiency virus; ORL, otolaryngologic. ${ }^{*} p$-Value $<0.05$ 
children and 18 (36\%) had CD4 count $<350$ cells $/ \mu \mathrm{L}$. Only 12 (24\%) children had viral load $<1,000$ copies/mL ( - Table2). Antiretroviral therapy (ART) was recorded among 43/50 (86\%) HIV-infected children.

\section{Prevalence and Manifestations of Otolaryngologic Lesions}

The overall prevalence of ORL lesions among all children in this study was $56 \%$. The prevalence of ORL lesions among HIV-infected children was $66 \%$ and it was $46 \%$ ( $p=0.004)$ among HIV-negative children. The frequency of ORL lesions was higher among HIV-infected children, undernourished children, and double orphans ( - Table $\mathbf{1}$ ).

Among HIV-infected children, the frequency of ORL lesions increased as indices of HIV disease severity worsened, whereas children on ART had lower prevalence of ORL lesions than those who were ART-naïve (-Table 2).

- Table 3 shows the distribution of ORL lesions among all the study participants according to their HIV status. Cervical adenopathy $(p=0.010)$ and hearing loss $(p=0.02)$ were the only lesions that were significantly related to HIV. The predominant organisms cultured from the ear swabs were gram-negative organisms. Only one child (HIV-negative)

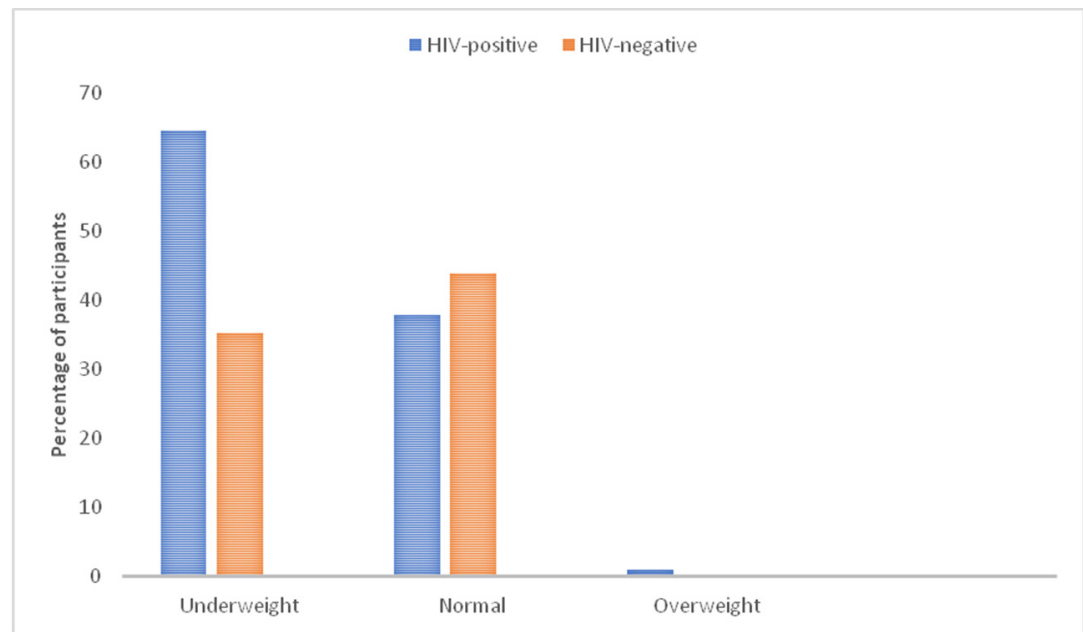

Fig. 1 Nutritional status categories by human immunodeficiency virus (HIV) status.

Table 2 Association between ORL lesions, WHO clinical staging, CD4 count, viral load, and ART treatment

\begin{tabular}{|c|c|c|c|}
\hline & \multicolumn{2}{|l|}{ ENT lesions } & \multirow[t]{2}{*}{$p$-Value } \\
\hline & Yes (\%) & No (\%) & \\
\hline \multicolumn{4}{|l|}{ WHO clinical stage } \\
\hline Stage 1 & $0(0.0)$ & $1(5.9)$ & \multirow[t]{4}{*}{$7.2(0.09$} \\
\hline Stage 2 & $5(15.1)$ & $1(5.9)$ & \\
\hline Stage 3 & $19(57.6)$ & $14(82.3)$ & \\
\hline Stage 4 & $9(27.3)$ & $1(5.9)$ & \\
\hline \multicolumn{4}{|l|}{ CD4 count } \\
\hline$<350$ cells $/ \mu \mathrm{L}$ & $10(30.3)$ & $8(47.1)$ & \multirow[t]{3}{*}{$2.2(0.3)$} \\
\hline $350-749$ cells/ $\mu \mathrm{L}$ & $14(42.4)$ & $7(41.2)$ & \\
\hline$\geq 750$ cells $/ \mu \mathrm{L}$ & $9(27.3)$ & $2(11.7)$ & \\
\hline \multicolumn{4}{|l|}{ Viral load } \\
\hline$<1,000$ & $9(27.27)$ & $3(17.6)$ & \multirow[t]{4}{*}{$1.6(0.65)$} \\
\hline $1,000-10,000$ & $6(18.18)$ & $3(17.6)$ & \\
\hline $10,000-100,000$ & $13(39.39)$ & $6(35.4)$ & \\
\hline$>100,000$ & $5(15.15)$ & $5(29.4)$ & \\
\hline \multicolumn{4}{|l|}{ ART treatment } \\
\hline Yes & $27(48.2)$ & $16(36.4)$ & \multirow[t]{2}{*}{$1.4(0.25)$} \\
\hline No & $6(51.8)$ & $1(63.6)$ & \\
\hline
\end{tabular}

Abbreviations: ART, antiretroviral therapy; ENT, ear-nose-throat; ORL, otolaryngologic; WHO, World Health Organization. 
grew Staphylococcus aureus, a gram-positive organism (-Table 4).

- Table 5 shows that bilateral and unilateral hearing loss was present in most HIV-infected children compared with
HIV-negative children. Among the children with hearing loss, other ear lesions were present in 9 (34.6\%) children: AOM and CSOM were seen in two and three HIV-infected children, respectively, whereas wax impaction occurred in two

Table 3 ORL lesions among study participants

\begin{tabular}{|l|l|l|l|}
\hline ORL lesion & $\begin{array}{l}\text { HIV-infected } \\
\boldsymbol{n}(\%)\end{array}$ & $\begin{array}{l}\text { HIV-negative } \\
\boldsymbol{n}(\%)\end{array}$ & -Value \\
\hline Wax impaction & $6(12.0)$ & $10(20)$ & 0.27 \\
\hline CSOM & $4(8.0)$ & $0(0.0)$ & 0.12 \\
\hline AOM & $2(4.0)$ & $2(4.0)$ & 1.00 \\
\hline Adenoidal hypertrophy & $0(0.0)$ & $3(6.0)$ & 0.24 \\
\hline Acute/chronic sinusitis & $10(20.0)$ & $10(20.0)$ & 0.96 \\
\hline Tonsillar enlargement & $10(20.0)$ & $7(14.0)$ & 0.42 \\
\hline Recurrent aphthous ulcer & $0(0.0)$ & $1(2.0)$ & 1.00 \\
\hline Candidiasis & $2(4.0)$ & $0(0.0)$ & 0.50 \\
\hline Herpes simplex & $5(10.0)$ & $0(0.0)$ & 0.06 \\
\hline Gingivitis & $1(2.0)$ & $0(0.0)$ & 1.00 \\
\hline Oral hairy leucoplakia & $1(2.0)$ & $0(0.0)$ & 1.00 \\
\hline Cervical adenopathy & $22(44.0)$ & $10(20.0)$ & $0.01^{*}$ \\
\hline Parotid enlargement & $5(10.0)$ & $0(0.0)$ & 0.06 \\
\hline Hearing loss & $18(36.0)$ & $8(16.0)$ & $0.02^{*}$ \\
\hline
\end{tabular}

Abbreviations: AOM, acute otitis media; CSOM, chronic suppurative otitis media; HIV, human immunodeficiency virus; ORL, otolaryngologic. ${ }^{*} p<0.05$.

Table 4 Bacterial isolates from culture of ear discharge

\begin{tabular}{|l|l|l|l|}
\hline \multicolumn{2}{|l|}{ HIV status } & Age $(\mathrm{y})$ & Bacterial isolates \\
\hline HIV-infected & $\# 1$ & 2 & Pseudomonas aeruginosa, Klebsiella pneumoniae \\
\hline \multirow{4}{*}{ CSOM } & $\# 2$ & 4 & P. aeruginosa, Proteus mirabilis \\
\cline { 2 - 4 } & $\# 3$ & 4 & Escherichia coli \\
\cline { 2 - 4 } & $\# 4$ & 14 & P. aeruginosa \\
\hline \multirow{2}{*}{ AOM } & $\# 5$ & 8 & Coagulase-negative Staphylococcus \\
\cline { 2 - 4 } & $\# 6$ & 11 & P. aeruginosa \\
\hline HIV-negative & & 2 & \multicolumn{2}{|l}{} \\
\hline AOM & $\# 7$ & 2 & P. aeruginosa \\
\cline { 2 - 4 } & $\# 8$ & 4 & Staphylococcus aureus \\
\hline
\end{tabular}

Abbreviations: AOM, acute otitis media; CSOM, chronic suppurative otitis media; HIV, human immunodeficiency virus.

Table 5 Hearing thresholds of HIV-infected and HIV-negative children

\begin{tabular}{|c|c|c|c|c|c|c|c|}
\hline \multicolumn{2}{|c|}{ Hearing assessment } & Total $n=100$ & HIV-infected $n=50$ & HIV-negative $n=50$ & $p$-Value & OR & $95 \% \mathrm{Cl}$ \\
\hline \multicolumn{8}{|l|}{ OAE } \\
\hline \multicolumn{2}{|c|}{ Pass } & $87(87 \%)$ & $45(90 \%)$ & $42(84 \%)$ & 0.37 & 0.58 & $0.18-1.19$ \\
\hline \multicolumn{2}{|c|}{ Fail } & $13(13 \%)$ & $5(10 \%)$ & $8(16 \%)$ & 0.37 & 1.71 & $0.52-5.66$ \\
\hline \multirow[t]{4}{*}{ PTA } & Hearing state & Total $n=62$ & $\begin{array}{l}\text { HIV-infected } \\
n=34\end{array}$ & $\begin{array}{l}\text { HIV-negative } \\
n=28\end{array}$ & $p$-Value & OR & $95 \% \mathrm{Cl}$ \\
\hline & Normal & $44(71 \%)$ & $18(53 \%)$ & $26(92.9 \%)$ & 0.001 & 11.5 & $2.36-53.55$ \\
\hline & Mild loss & $7(11.3 \%)$ & $5(14.7 \%)$ & $2(7.1 \%)$ & 0.44 & 0.45 & $0.08-2.50$ \\
\hline & Moderate loss & $11(17.7 \%)$ & $11(32.3 \%)$ & $0(0 \%)$ & 0.01 & 2.2 & $1.64-3.00$ \\
\hline
\end{tabular}

Abbreviations: $\mathrm{Cl}$, confidence interval; HIV, human immunodeficiency virus; OAE, otoacoustic emission; OR, odds ratio; PTA, pure tone audiometry. 
HIV-infected children and two (7.7\%) HIV-negative children, respectively.

Using PTA, hearing loss was detected 18 HIV-infected children. Six (33.3\%) children had conductive hearing loss (CHL), four $(22.2 \%)$ had sensorineural hearing loss, and two (11.1\%) had mixed hearing loss. The remaining two HIV-infected children became restless and did not complete the PTA test; hence, the type of deafness could not be categorized. Among the HIV-negative children, 28 children had PTA and hearing loss was detected in 2 (7.1\%) children; both of whom had mixed hearing loss.

\section{Discussion}

This study found that ORL lesions are common in both HIV-infected and HIV-negative children. The prevalence of ORL lesions in HIV- infected children was $66 \%$ and it was $46 \%$ in HIV-negative children. The proportion of ORL lesions increased as HIV disease severity worsened and reduced with use of ART. The prevalence of ORL lesions found in this study is high although lower than the prevalence reported among Angolan children..$^{9}$ In Angola, the prevalence of ORL lesions was $92 \%$ in HIV-infected children and $72 \%$ in HIV-negative children whereas in Brazil $90 \%$ of the HIV- infected children were documented to have at least one ENT lesion. ${ }^{11}$ Hadfield et $\mathrm{al}^{7}$ in the United Kingdom also reported a high prevalence of ENT (ear-nose-throat) lesions (90\%) among HIV- infected children. All these studies were conducted at least 8 years prior to this study. The difference between the prevalence rate in this study and other reports may be due to the decline in new pediatric HIV infections globally and improved access to art.

In general, HIV-infected children had more ORL lesions than HIV-negative children. Cervical adenopathy and hearing loss were the only ORL lesions that showed significant association with pediatric HIV infection in this study. Although cervical adenopathy was common among HIV-infected children, the prevalence among HIV-negative children was also high. There is a myriad of etiologies of cervical adenopathy in children regardless of HIV status. Many of these etiologies are benign infections such as viral upper respiratory tract infections. Less commonly are chronic conditions such as tuberculosis, autoimmune diseases, and malignancies.

Hearing loss was another ORL lesion that was common among HIV-infected children. The prevalence of hearing loss among children with HIV in this study was 36\% that is comparable to $33 \%$ by Christopher et $\mathrm{al}^{14}$ in Uganda and $33.8 \%$ by Chao et $\mathrm{a}^{15}$ in Peru. When compared with HIV-negative children, a prevalence of $16 \%$ in this study is comparable to $15 \%$ recorded in Angola. ${ }^{9}$ All children with CSOM in this study were HIV infected and had higher prevalence of hearing loss than children with wax impaction, who comprised more HIV-negative children. Middle ear infections and often associated tympanic membrane perforations are the primary mechanisms of hearing loss described in HIV-infected children., ${ }^{9,12,16-18}$ These mechanisms were demonstrated in data from Peru and Malawi where CHL was the predominant form of hearing loss among HIV-infected children. ${ }^{15,19}$ In both countries, middle ear infections and perforation of the tympanic membrane were more prevalent among HIV-infected children with subsequent $\mathrm{CHL}$ than sensorineural and mixed hearing loss. In this Nigerian study, CHL was seen more among HIV-infected children due to the higher prevalence of otitis media among them unlike HIV-negative children who had more cases of SNHL.

The high prevalence of hearing loss suggests that HIV infection is a significant contributor to hearing loss in children and may require more attention in public health efforts to control deafness. Hitherto, deafness has not been given much consideration as a complication or morbidity resulting from the HIV infection and/or from treatment of HIV infection. As observed in this study, HIV-negative children who had hearing impairment were mostly younger than 5 years, whereas HIV-infected children with hearing loss who were mostly older than 5 years. It is possible that the hearing loss among uninfected children may be due to other viral infections such as cytomegalovirus (CMV), measles, or from perinatal events. ${ }^{20,21}$ Therefore, accepting that HIV is now important in the epidemiology of hearing loss ${ }^{18}$ and controlling HIV infection may lead to reduction in the prevalence of hearing loss in children.

The bacterial isolates among HIV-infected children with otitis media were predominantly gram-negative organisms such as Klebsiella spp., Pseudomonas spp., and Proteus spp. This is comparable to other reports..$^{12,22}$ There is a study, which reported predominance of Streptococcus pneumoniae ${ }^{23}$ conducted before pneumococcal vaccine and was included in the routine immunization program, which may explain the predominance of S. pneumoniae, although some other recent reports have shown predominance of S. pneumoniae in isolates from middle ear discharge. ${ }^{24}$ Another factor that may modify the spectrum of predominant bacteria is the emergence of drug-resistance organisms that are now being seen among community-acquired infections.

In this study, there was scarce reporting of lesions that had been previously described to occur commonly in HIV infection such as oral candidiasis, herpes simplex, hairy leukoplakia, and Kaposi's sarcoma. This probably could be explained by the fact that a large percentage of the HIV-infected children were on ART, which halts progression of the disease to more severe stages in which the aforementioned lesions occur.

\section{Conclusion}

The ORL lesions occur more commonly among HIV-infected children than HIV-negative children. Use of ART improves the clinical course and outcome of HIV-infected children resulting in fewer ORL lesions. Hearing loss is associated with HIV infection, and evaluation for hearing loss should be routine for all HIV-infected children.

\section{Conflict of Interest}

None. 


\section{References}

1 UNAIDS. 2012. Getting to zero. Regional fact sheet [Internet]. 2012 [cited July 9, 2018]. Available at: http://files.unaids. org/en/media/unaids/contentassets/documents/epidemiology/2012/gr2012/20121120_FactSheet_Global_en.pdf. Accessed July 9,2018

2 Ogunbosi BO, Oladokun RE, Brown BJ, Osinusi KI. Prevalence and clinical pattern of paediatric HIV infection at the University College Hospital, Ibadan, Nigeria: a prospective cross-sectional study. Ital J Pediatr 2011;37:29-34

3 Adebola AR, Adeleke SI, Mukhtar M, Osunde OD, Akhiwu BI, Ladeinde A. Oral manifestation of HIV/AIDS infections in paediatric Nigerian patients. Niger Med J 2012;53(3):150-154

4 UNAIDS2016. Global AIDS Update [Internet]. 2016 [cited July 11, 2018]. Available at: http://www.unaids.org/en/resources/ documents/2016/Global-AIDS-update-2016. Accessed July 11, 2018

5 Devendra A, Makawa A, Kazembe PN, Calles NR, Kuper H. HIV and childhood disability: a case-controlled study at a paediatric therapy centre in Lilongwe, Malawi. PLoS One 2013;8(12):e84024

6 Hanass-Hancock J, Myezwa H, Nixon SA, Gibbs A. "When I was no longer able to see and walk, that is when I was affected most": experiences of disability in people living with HIV in South Africa. Disabil Rehabil 2015;37(22):2051-2060

7 Hadfield PJ, Birchall MA, Novelli V, Bailey CM. The ENT manifestations of HIV infection in children. Clin Otolaryngol Allied Sci 1996;21(1):30-36

8 Singh A, Georgalas C, Patel N, Papesch M. ENT presentations in children with HIV infection. Clin Otolaryngol Allied Sci 2003;28(3):240-243

9 Taipale AT, Pelkonen M, Taipale I, et al. Otolaryngological findings and hearing in HIV-positive and HIV-negative children in a developing country. Euro Arch Otolaryngol 2011;286(10):1527-1532

10 Opoku-Buabeng J, Dompreh A. Ear, nose and throat lesions in HIV/AIDS patients in Komfo Ankoye Teaching Hospital, Kumasi, Ghana. J West Afr Coll Surg 2012;2(2):10-22

11 Gondim LA, Zonta RF, Fortkamp E, Schmeling RO. Otorhinolaryngological manifestations in children with human immunodeficiency virus infection. Int J Pediatr Otorhinolaryngol 2000;54(2-3):97-102

12 Tiedt NJ, Butler IR, Hallbauer UM, et al. Paediatric chronic suppurative otitis media in the free state province: clinical and audiological features. S Afr Med J 2013;103(7):467-470
13 World Health Organisation. Prevention of blindness and deafness-grades of hearing impairment [Internet]. 2018 [cited July 9, 2018]. Available at: http://www.who.int/pbd/deafness/ hearing_impairment_grades/en/. Accessed July 9, 2018.

14 Christopher N, Edward T, Sabrina BK, Agnes N. The prevalence of hearing impairment in the 6 months- 5 years HIV/ AIDS-positive patients attending paediatric infectious disease clinic at Mulago Hospital. Int J Pediatr Otorhinolaryngol 2013;77(2):262-265

15 Chao CK, Czechowicz JA, Messner AH, et al. High prevalence of hearing impairment in HIV-infected Peruvian children. Otolaryngol Head Neck Surg 2012;146(2):259-265

16 Eziyi J, Amusa Y, Akinpelu O, Adeniji A, Ogunniyi O. Audiological pattern of hearing loss at the Obafemi Awolowo University Teaching Hospital Complex Ile-Ife, Nigeria. IJORL 2008;8(2):1-6

17 Torre P, Zeldow B, Hoffman $\mathrm{H}$, et al. Hearing loss in perinatally human immunodeficiency virus-infected and human immunodeficiency virus-exposed but un-infected children and adolescents. Pediatr Infect Dis J 2012;31(8):835-841

18 Ensink RJ, Kuper H. Is hearing impairment associated with HIV? A systematic review of data from low- and middle-income countries. Trop Med Int Health 2017;22(12):1493-1504

19 Hrapcak S, Kuper H, Bartlett P, et al. Hearing loss in HIV-Infected children in Lilongwe, Malawi. PLoS One 2016;11(8):e0161421

20 Dunmade AD, Segun-Busari S, Olajide TG, Ologe FE. Profound bilateral sensorineural hearing loss in Nigerian children: any shift in etiology? J Deaf Stud Deaf Educ 2007;12(1):112-118

21 Olusanya BO. Neonatal hearing screening and intervention in resource-limited settings: an overview. Arch Dis Child 2012;97(7):654-659

22 Ugochukwu EF, Ezechukwu CC, Undie N, Akujobi C. Pattern of pathogens in ear discharge of HIV-infected children in Nnewi, Southeast Nigeria. Niger J Clin Pract 2007;10(2):130-136

23 Shapiro NL, Novelli V. Otitis media in children with vertically-acquired HIV infection: the Great Ormond Street Hospital experience. Int J Pediatr Otorhinolaryngol 1998;45(1):69-75

24 Madhi SA, Govender N, Dayal K, et al. Bacterial and respiratory viral interactions in the etiology of acute otitis media in HIV-infected and HIV-uninfected South African children. Pediatr Infect Dis J 2015;34(7):753-760 